\title{
Innovative WiMAX Broadband Internet Access for Rural Areas of Vietnam using TV Broadcasting Ultra-High Frequency (UHF) Bands
}

\author{
Tan T. Duc ${ }^{\mathrm{a}}$, Tuyen T. Duc ${ }^{\mathrm{a}}$., Dung D. Do ${ }^{\mathrm{b}}$, Hoang V. Nguyen ${ }^{\mathrm{b}}$ \\ ${ }^{a} U$ niversity of Engineering and Technology, Vietnam National U niversity, H anoi, Vietnam \\ ${ }^{\mathrm{b}} \mathrm{Bac} \mathrm{H}$ a International U niversity, Vietnam
}

\begin{abstract}
This paper presents a case study of the proposed digital television based WiMAX wireless network to provide broadband Internet service in the suburban/rural area of BacNinh province, Vietnam. Advantages of the combination between digital television and WiMAX in the UHF broadcasting bands are discussed and compared with existing WiMAX in the microwave frequency bands. Commercially available equipments for both base-station and subscriber station are evaluated and incorporated in the link budget study and simulation.
\end{abstract}

Key words - Broadcasting, digital television, light of site (LOS), outdoor propagation, WiM AX, UHF.

\section{INTRODUCTION}

In Vietnam and some other countries in the Asia-Pacific region, there is a wide digital divine between the urban cities and the suburban/rural areas. Low income and high illiteracy coupled with limited access to information technology in these rural communities are three of the main reasons for the current digital divine gap. The situation gets even worse in areas which have a low population density and have an elevated terrain profile of high hills or mountains. This is because conventional access such as Asymmetric Digital Subscriber Line (ADSL) is physically difficult to deploy.

Recent advance in broadband wireless technologies such as Worldwide Interoperability for Microwave Access (WiMAX) [1], Long-Term Evolution (LTE) [2] and Wireless Regional Area Networks (WRANs) [3] promises a potential solution to bridge this digital divine gap. However, high licensed/deployment costs (in the case ofWiMAX/LTE) and/or technical obstacles (in the case of WRAN) still keep these promising technologies either operated in developed regions with dense population or being tested in field-trials. The current switching from analog television (TV) to digital TV in many places around the world has freed-up a large portion of Ultra High Frequency (UHF) band, which, as expected, make it a suitable frequency range for broadband wireless access [4], [5]. Moreover, the superior propagation characteristic of UHF signals results in a larger coverage cell for a single base station transmitter. Essentially, there is less required base station for a given coverage area and hence lower deployment cost.

In this study, we are investigating the feasibility of a digital television based WiMAX wireless network operating in UHF broadcasting bands in the BacNinh province, Vietnam. The proposed approach is expected to provide an economical and sustainable broadband Internet service to the suburban/rural communities in Vietnam or other countries facing similar digital divine challenge.

The paper is organized as follows. In Section 2, we introduce the brief background digital television based WiMAX and comparison with existing WiMAX. Section 3 presents our implementation methodology. Simulation results to demonstrate the efficiency of our method and verifications are presented in Section 4 and 5. Section 6 concludes the paper with discussions on the results and remarks for future work.

\section{BRIEF BACKGRound Digital TELEVISION BASED WIMAX AND COMPARISON WITH EXISTING WIMAX}

Fig. 1 shows the proposed digital television based WiMAX wireless network. In essence, it is a combination of one-way traffic digital television broadcasting with two-way traffic WiMAX Internet/IP data stream. Both technologies operate in UHF bands and are broadcasted over-the-air from a single TV tower to many customers within the tower's coverage cell. The customer premise equipment typically consists of an outdoor VHF/UHF antenna, a digital transceiver terminal having outputs for television and data stream signals, and a personal computer.

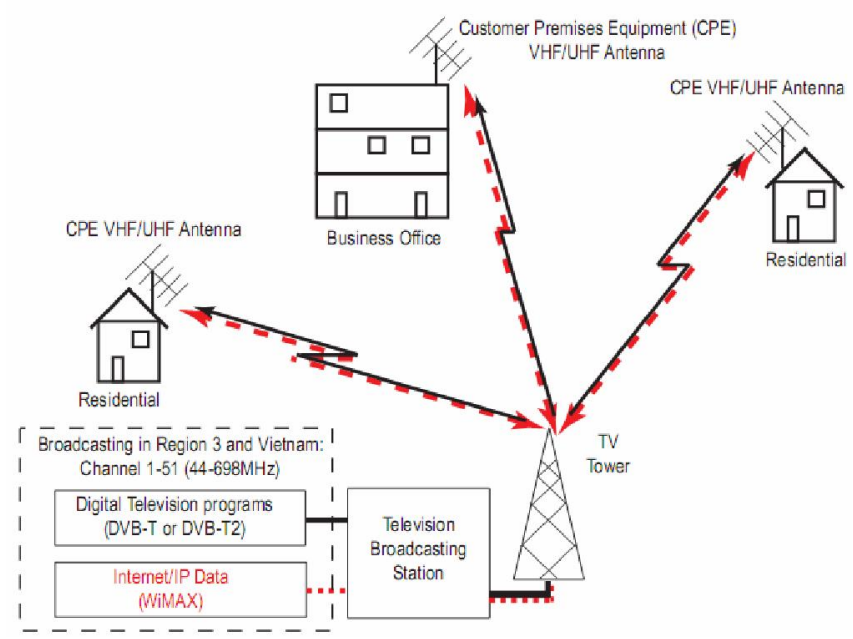

Fig. 1. Proposed digital television based WiMAX network using ultra high frequency (UHF) broadcasting bands to provide data service in suburban/rural area of Bac Ninh, Vietnam.

The WiMAX system in the proposed network operates in UHF bands where digital television channels do not exist within the coverage region and therefore will not cause any harmful interference with existing digital television channels. Since the two technologies (DVB-T and WiMAX) have many common factors as can be seen in Tab. 1, its combination can potentially provide an economical and sustainable network by sharing tower, transmitting antenna, and digital modulator/transmitter/amplifier for the downlink traffic. For uplink traffic, Digital Video BroadcastingReturn Channel Terrestrial can be used to complete the communication link. 


\section{Pre-print}

TABLE I. DIGITAL VIDEO BROADCASTING - TERRESTRIAL (DVB-T) AND WIMAX KEY RF CHARACTERISTIC COMPARISON.

\begin{tabular}{|l|c|c|}
\hline \multicolumn{1}{|c|}{ Items } & DVB-T & W iM AX \\
\hline $\begin{array}{l}\text { Frequency band with } \\
\text { commercially available } \\
\text { equipment }\end{array}$ & $\begin{array}{c}174-230 \mathrm{MHz} \\
470-862 \mathrm{MHz}\end{array}$ & $\begin{array}{c}450-700 \mathrm{MHz} \text { (next BWA) [6] } \\
2300-2500 \mathrm{MHz} \\
3600 \mathrm{MHz}\end{array}$ \\
\hline RF PHY & OFDM & OFDM \\
\hline Modulation & $\begin{array}{c}\text { 64QAM, } \\
\text { 16QAM } \\
\text { QPSK }\end{array}$ & $\begin{array}{c}\text { 64QAM, 16QAM, QPSK, } \\
\text { BPSK }\end{array}$ \\
\hline Channel BW & $6,7,8 \mathrm{MHz}$ & $3.5,5,6,7,10 \mathrm{MHz}$ \\
\hline Adaptive & None & yes \\
\hline
\end{tabular}

It is well known that low UHF signal has a superior propagation characteristic compared with high UHF and microwave frequency signals. As a result, WiMAX system operating in low UHF bands has a longer reach and larger coverage area than current WiMAX at 2.5 or $3.5 \mathrm{GHz}$ for the same transmitting power. With a lower path loss, better coverage and low cost and simple deployment advantages, digital television based WiMAX network operating in low UHF bands provide a compliment to 2.5 or $3.5 \mathrm{GHz}$ networks in the suburban/rural regions.

\section{IMPLEMENTATION METHODOLOGY}

To validate and to test the network, we first conduct a throughout survey of commercially available WiMAX equipments operated in the UHF bands. Next, a system study and frequency assessment are performed to select a center operating frequency, bandwidth, power for the system.

\section{A. Commercial WiMAX Equipment in the UHF bands}

At the current time, Harris Stratex Networks is the only supplier that provides both base station and subscriber station WiMAX equipment in the low UHF bands. The base station and subscriber station models are HSX StarMAX 6000 and HSX StarMAX 2160, respectively [6]. Tab. 2 summarizes the key RF specifications of the equipment, which will be later used in the link budget calculation. Both models support time division duplexing which is a more suitable for asymmetrical traffic commonly found in WiMAX network.

TABLE II. KEY RF SPECIFICATIONS For COMMERCIALly AVAILABLE BASE STATION (BS) AND SUBSCRIBER STATION (SS) WIMAX EQUIPMENT AT UHF BANDS

\begin{tabular}{|l|c|c|}
\hline \multicolumn{1}{|c|}{ Items } & Base station & Subscriber station \\
\hline Frequency & $410-470 \mathrm{MHz}$ & $410-470 \mathrm{MHz}$ \\
\hline RChannel BW & $1.75,2.5,3 \mathrm{MHz}$ & $1.75,2.5,3 \mathrm{MHz}$ \\
& $3.5,5,6,7 \mathrm{MHz}$ & $3.5,5,6,7 \mathrm{MHz}$ \\
\hline Tx Power & $+42 \mathrm{dBm}$ & $+30 \mathrm{dBm}$ \\
\hline Rx Sensitivity & $-95 \mathrm{dBm}$ & $-95 \mathrm{dBm}$ \\
\hline & @ 5MHz BPSK & @ 5MHz BPSK \\
Modulation & 64QAM, & 64QAM, 16QAM \\
& 16QAM & QPSK, BPSK \\
\hline Duplex Method & QPSK, BPSK & TDD \\
\hline
\end{tabular}

\section{B. Commercial WiMAX Equipment in the UHF bands}

Our current site survey indicates that a line-of-site (LOS) or near LOS condition is satisfied in the coverage region in Bac Ninh province, Vietnam and a cumulative bandwidth of approximately 1.8 megabits per second (Mbps) (1.5Mbps for downlink and $0.3 \mathrm{Mbps}$ for uplink traffics) is required.
Current national spectrum allocation indicates the UHF bands between $410-470 \mathrm{MHz}$ are currently serviced for fixed and land mobile communication with a specific band of $450-470 \mathrm{MHz}$ is used for narrow-band 64, 128 and 384kbps microwave systems [7]. Moreover, there is no existing digital television channel within the UHF bands from 410$470 \mathrm{MHz}$.

\section{Study Case in BaCninh, Vietnam}

Fig. 2 shows the terrain map of Bac Ninh province and neighboring provinces in the northern part of Vietnam with a zoom-in of our study area within the city of Bac Ninh. The base station (BS) antenna is located at the Bac Ninh telecommunications center and three subscriber station (SS) antennas are located at points $\mathrm{Rx}_{\mathrm{i}}, \mathrm{i}=1,2$, and 3 and within 2 $\mathrm{km}$ radius to the base station as shown in Fig. 2. The BS antenna can be placed between $30 \mathrm{~m}$ to $60 \mathrm{~m}$ height, while SS antenna is placed at $10.5 \mathrm{~m}$ height.

\section{A. Propagation Path Loss}

For the above BS and SS antenna heights and operating frequency in the $410-470 \mathrm{MHz}$ UHF band, the Hata propagation model is selected to compute the propagation path loss for LOS condition [8]. Since the study area is a mixture of suburban and rural areas, both suburban and rural Hata models are selected for comparison. Fig. 3 shows the computed path loss versus the cell radius from the BS antenna. Within a $2 \mathrm{~km}$ cell radius, the loss varies between $-96 \mathrm{~dB}$ and $-118 \mathrm{~dB}$ for the Hata rural and suburban models, respectively.

\section{B. Link Budget}

Table 3 summarizes the parameters used at the BS transmitting antenna and SS receiving antenna for the link budget calculation. Maximum power is first selected to study the effective link reliability at the $2 \mathrm{~km}$ radius and maximum achievable distance for a $90 \%$ link reliability for both uplink and downlink traffics for QPSK modulation.

Table 4 shows the results for two BS antenna height of 30 $\mathrm{m}$ and $60 \mathrm{~m}$. The excess link surplus indicates that transmit power can be reduced or higher bit rate (higher modulation such as 16QAM or 64QAM) can be accommodated.

TABLE III. PARAMETERS USED IN THE LINK BUdGET ANALYSIS

\begin{tabular}{|l|c|c|}
\hline \multicolumn{1}{|c|}{ I tems } & $\begin{array}{c}\text { Base station } \\
\text { (Downlink) }\end{array}$ & $\begin{array}{c}\text { Subscriber station } \\
\text { (Uplink) }\end{array}$ \\
\hline Transmit Power & $42 \mathrm{dBm}$ & $30 \mathrm{dBm}$ \\
\hline $\mathrm{NF}$ & $8 \mathrm{~dB}$ & $6 \mathrm{~dB}$ \\
\hline Sensitivity & $-95 \mathrm{dBm}$ & $-90 \mathrm{dBm}$ \\
\hline Antenna gain & $18 \mathrm{dBi}$ & $12 \mathrm{dBi}$ \\
\hline Capacity & $1.5 \mathrm{Mbps}$ & $0.3 \mathrm{Mbps}$ \\
\hline Modulation & QPSK & QPSK \\
\hline Reliability margin & $90 \%$ & $90 \%$ \\
\hline
\end{tabular}

TABLE IV. LINK BUDGET RESULTS

\begin{tabular}{|c|c|c|}
\hline Items & Downlink & Uplink \\
\hline \multicolumn{3}{|l|}{$h_{T X}^{1}=30 \mathrm{~km}$} \\
\hline Reliability @ 2km & $100 \%$ & $100 \%$ \\
\hline Maximum cell radius for $90 \%$ link & $30 \mathrm{~km}$ & $30 \mathrm{~km}$ \\
\hline Link surplus @ 2km & $41.5 \mathrm{~dB}$ & $29.5 \mathrm{~km}$ \\
\hline \multicolumn{3}{|l|}{$h_{T X}^{1}=60 \mathrm{~km}$} \\
\hline Reliability @ 2km & $100 \%$ & $100 \%$ \\
\hline
\end{tabular}




\section{Pre-print}

\begin{tabular}{|l|c|c|}
\hline Maximum cell radius for 90\% link & $49.33 \mathrm{~km}$ & $30.38 \mathrm{~km}$ \\
\hline Link surplus @ 2km & $46.3 \mathrm{~dB}$ & $39.3 \mathrm{~km}$ \\
\hline
\end{tabular}

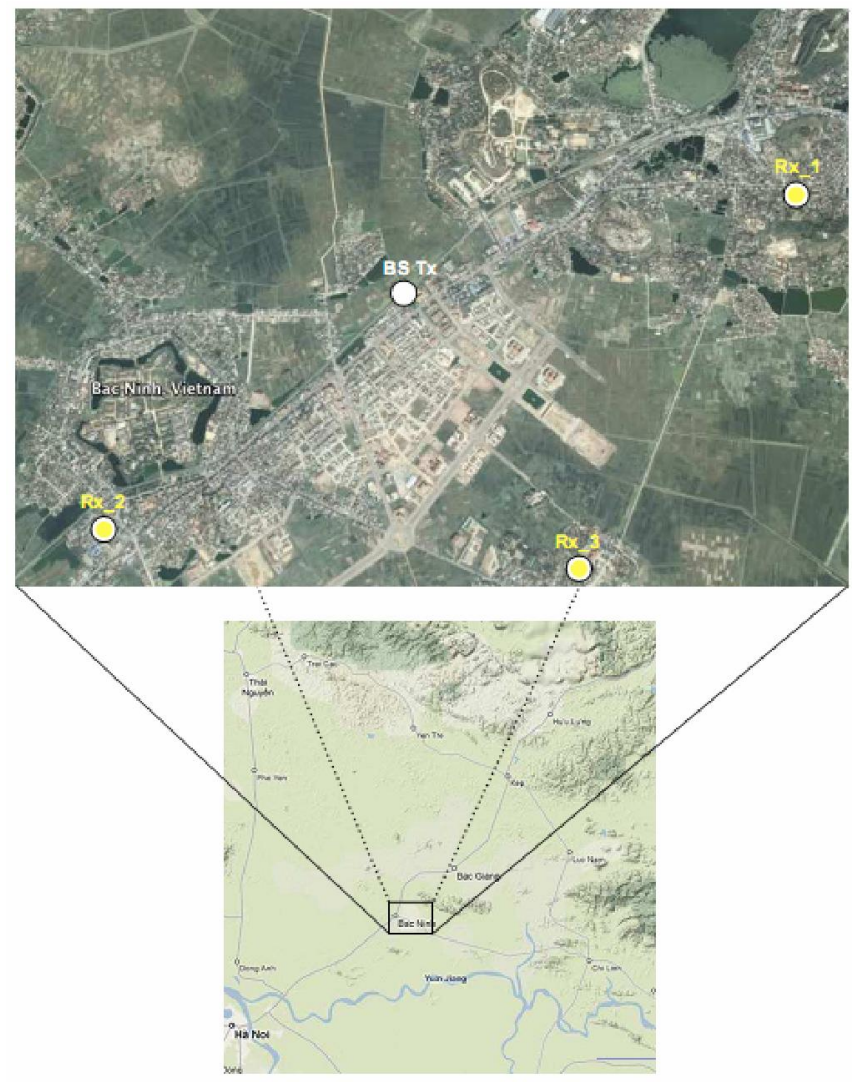

Fig. 2. Terrain map of Bac Ninh province and neighboring provinces with a zoom-in of the study area in the city of Bac Ninh.

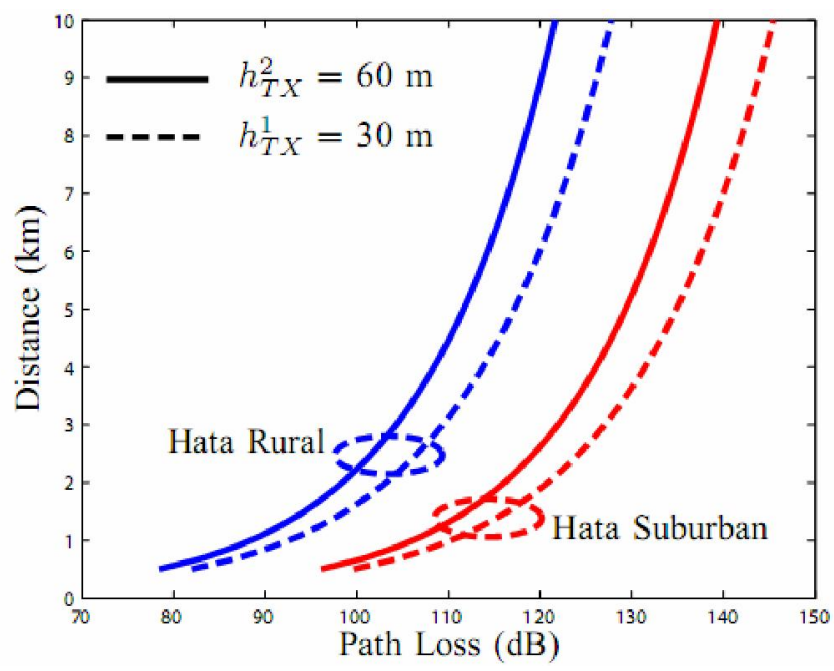

Fig. 3. Propagation path loss for UHF signal at $450 \mathrm{MHz}$ frequency using sub-urban and rural Hata models for two different base station transmiting antenna height, $h_{T X}^{1}=30 \mathrm{~m}$ and $h_{T X}^{2}=60 \mathrm{~m}$. The receiving antenna height is $h_{R X}=10.5 \mathrm{~m}$

\section{THEORETICAL VERIFICATION}

\section{A. Software Package}

The network operation is verified using Remcom Wireless Insite which is site-specific radio propagation software for the analysis and design of wireless communication systems. It provides efficient and accurate predictions of propagation and communication channel characteristics in complex urban, indoor, rural and mixed path environments [9].

The virtual building and terrain environment is either constructed using Wireless InSite's editing tools or imported from a number of popular formats. More than 1000 building has been imported using Wireless Insite's editing tool (see Fig. 5). The terrain file of BacNinh province is available from the Shuttle Rada Topography Mission [10]. The study area is between $21^{\circ}$ and $21^{\circ} 15^{\prime}$ North and $105^{\circ} 55^{\prime}$ and $106^{0} 15^{\prime}$ East. The study area is next populated with actual buildings, landscapes, transmitting and receiving stations with specifications given in the above tables. Fig. 5 shows the radio frequency power distribution in the study area with a single transmitting antenna mounted on a BS tower located at $21^{\circ} 11^{\prime} 29.5$ " North and $106^{\circ} 4^{\prime} 40.2^{\prime \prime}$ East.

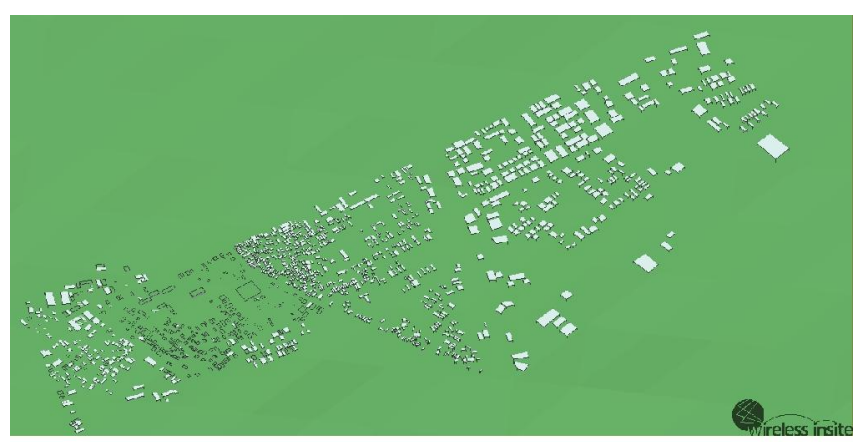

Fig. 4. The virtual building of more 1000 highest building in BacNinh

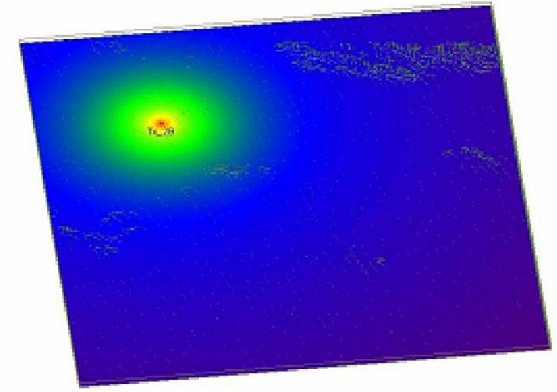

Fig. 5. The radio frequency power distribution in the study area with a single transmitting antenna

Wireless InSite makes these calculations by shooting rays from the transmitters, and propagating them through the defined environment. These rays interact with environmental features and make their way to receivers. Fig. 6 shows the simulation result of the propagation rays between a single transmitter (106.067 longitude, 21.1801 latitude at $450 \mathrm{MHz}, \mathrm{BW}=5 \mathrm{MHz}, \mathrm{P}=42 \mathrm{dBm}$ ) and a single receiver (106.067 longitude, 21.1801 latitude) using the directional antennas. The effects of each interaction along a ray's path to the receiver are evaluated to determine the resulting signal level. At each receiver location, rays are combined and evaluated to determine signal characteristics such as path loss, delay, direction of arrival, and impulse response. 


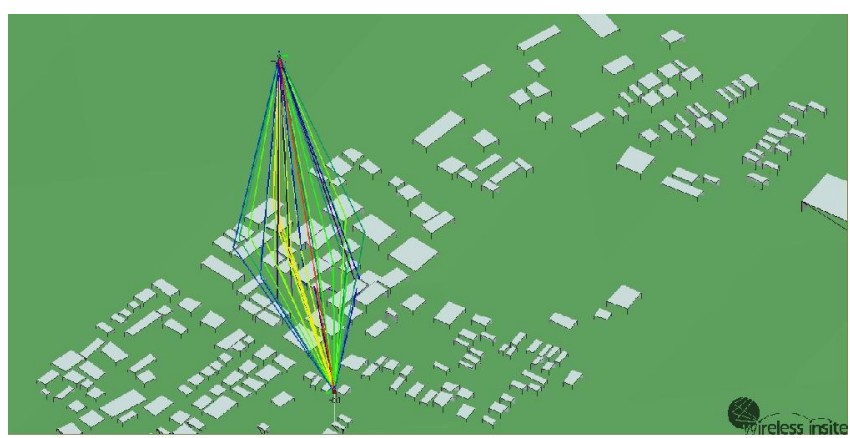

Fig. 6. Rays reaching receiver are reflected off and/or transmitted though buildings.

\section{B. Simulation Results}

Tables 5 and 6 summarize the simulation results of the maximum coverage area per BS and the number of required BS to provide a complete coverage in the study area. In table 5, the antennas are directional antenna with $18 \mathrm{dBi}$ and Yagi antenna with $12 \mathrm{dBi}$ for BS and SS respectively. On the other hand, the antennas are isotropic antennas at both BS and SS in table 6. As can be seen, the number of BS is always lower than that of conventional WiMAX system operating at $2.5 \mathrm{GHz}$ and $3.5 \mathrm{GHz}$. As a result, the proposed system will have a lower overall deployment and operating costs.

TABLE V. REMCOM WIRELESS INSITE RESULT COMPARING MAXIMUM DisTANCE AND COVERAGE FOR WIMAX AT 450 MHZ, 2.5 GHZ AND 3.5 GHZ USING DIRECTIONAL ANTENNA IN BS AND SS.

\begin{tabular}{|l|c|c|c|}
\hline \multicolumn{1}{|c|}{ I tems } & $450 \mathrm{M} \mathrm{Hz}$ & $2.5 \mathrm{G} \mathrm{Hz}$ & $3.5 \mathrm{G} \mathrm{Hz}$ \\
\hline Maximum distance $(\mathrm{km})$ & 36.92 & 10.24 & 7.01 \\
\hline Coverage area $\left(\mathrm{km}^{2}\right)$ & 52700 & 1124 & 360 \\
\hline Required number of BS & 2 & 8 & 17 \\
\hline
\end{tabular}

TABLE VI. REMCOM WIRELESS INSITE RESULT COMPARING MAXIMUM DisTANCE AND COVERAGE FOR WIMAX AT $450 \mathrm{MHZ}, 2.5 \mathrm{GHZ}$, AND 3.5 GHZ USING ISOTROPIC ANTENNA IN BS AND SS.

\begin{tabular}{|l|c|c|c|}
\hline \multicolumn{1}{|c|}{ Items } & $450 \mathrm{M} \mathrm{Hz}$ & $2.5 \mathrm{G} \mathrm{Hz}$ & $3.5 \mathrm{G} \mathrm{Hz}$ \\
\hline Maximum distance $(\mathrm{km})$ & 6.44 & 1.68 & 1.21 \\
\hline Coverage area $\left(\mathrm{km}^{2}\right)$ & 837 & 11 & 5.6 \\
\hline Required number of BS & 7 & 95 & 147 \\
\hline
\end{tabular}

\section{CONCLUSION}

This work investigates a practical implementation of a DTV based WiMAX network to provide a potential low cost and sustainable broadband services to the suburban/rural areas in Vietnam. The study outlines the advantages of the combination of the two technologies and selects commercial available WiMAX equipments for the field-trials. Simulation results based on Wireless Insite software have shown the ability to apply to real applications. In the future, measurements will be carried out to verify the simulated results.

\section{ACKNOWLEDGMENT}

This research was partly supported by TRIG-B project.

\section{REFERENCES}

[1] Jeffrey G. Andrews, Arunabha Ghosh, and Rias Muhamed, Fundamentals of WiMAX: Understanding broadband wireless networking, Prentice Hall, 2007.
[2] Ekstrom, H., el. at., Technical solutions for the $3 \mathrm{G}$ long-term evolution, IEEE communication magazine, Vol. 33 (3), 2006, pp. 38 45 .

[3] Stevenson C., Chouinard G., Zhongding Lei, Wendong $\mathrm{Hu}$, Shellhammer S., Caldwell W., The IEEE 802.22: the first cognitive regional area network standard, IEEE communications magazine, Vol. 47(1), 2009, pp. 130-138.

[4] M. Nishi, Y. Atsumi, T. Toyota, and T. Yoshida, "Proposal of new information traffic platforms in UHF band for communication and broad-casting services" in Global Telecommunications Conf GLOBECOM'01, San Antonio, TX, USA, Nov. 2001, pp. 552 - 556.

[5] Honcharenko W., Kruys J.P., Lee D.Y., Shah N.J., Broadband wireless access, IEEE Communication Magazines, Vol. 35(1), 1997, pp. 20-26.

[6] http://www.harrisstratex.com/products/starmax/fpWimax.asp

[7] Radio frequency channel arrangement for Fixed and Mobile services 30- 1000MHz, http://www.rfd.gov.vn.

[8] T. S. Rappaport, Wireless Communications: Principles and Practice, Prentice Hall, 2002.

[9] The Wireless Insite user's manual, http://www.remcom.com/wirelessinsite.

[10] The Shuttle Radar Topography Mission, Rev. Geophysics, 45, RG2004, doi: 10.1029/2005RG000183. 